\title{
Synthesis and Characterization of a Carbon Nanotube-Dendron Series for Efficient siRNA Delivery
}

M. Antonia Herrero ${ }^{a, b}$, Francesca M. Toma $^{a, c}$, Kouloud Al-Jamal $^{d}$, Kostas Kostarelos ${ }^{d}$, Alberto Bianco $^{e}$, Fouzia Bano $^{c, f}$, Loredana Casalis ${ }^{c, f}$, G. Scoles ${ }^{c, f}$, M. Prato $^{a, *}$

${ }^{a}$ Department of Pharmaceutical Sciences, Trieste University, 34127 Trieste, Italy

${ }^{\text {b }}$ Departamento de Química Orgánica, Facultad de Química, Universidad de Castilla-La Mancha, 13071 Ciudad Real, Spain

${ }^{\mathrm{c}}$ SISSA, 30014 Trieste, Italy

${ }^{\mathrm{d}}$ Nanomedicine Laboratory, Centre for Drug Delivery Research, The School of Pharmacy, University of London, UK

${ }^{\mathrm{e}} \mathrm{CNRS}$, Institut de Biologie Moléculaire et Cellulaire, Immunologie et Chimie Thérapeutiques, 67000 Strasbourg, France

${ }^{\mathrm{f}}$ Elettra, Synchrotron Laboratories, Trieste, Italy

\section{SUPPORTING INFORMATION}




\begin{tabular}{|c|c|c|c|c|}
\hline & \%Weight & Funct/C (a) & $\mathbf{~ m m o l / g ~ ( b ) ~}$ & $\begin{array}{c}\text { Kaiser test } \\
(\mathbf{m m o l} / \mathbf{g})(\mathbf{c})\end{array}$ \\
\hline $\begin{array}{c}\text { Alkylated } \\
\left(\mathrm{G}_{0}\right) \text { dendron } \\
\text { MWNT 2 }\end{array}$ & 98,6 & 1915 & 0,0429 & 0,072 \\
\hline $\begin{array}{c}\text { Alkylated } \\
\left(\mathrm{G}_{1}\right) \text { dendron } \\
\text { MWNT 4 }\end{array}$ & 96,2 & 1476 & 0,0543 & 0,111 \\
\hline $\begin{array}{c}\text { Alkylated } \\
\left(\mathrm{G}_{2}\right) \text { dendron } \\
\text { MWNT 6 }\end{array}$ & 94,4 & 2049 & 0,0384 & 0,212 \\
\hline
\end{tabular}

Table S1. The weight percentage was calculated at $450^{\circ} \mathrm{C}$. (a) Number of functional groups per each carbon atom and (b) mmol/g calculating by means of TGA analysis; (c) Kaiser test's result compared to TGA.

The data reported in Table S1 show a good correlation between the generations of the alkylated dendrons, even though the degree of functionalization obtained in the first synthesis was lower than that obtained after repetition of the preparation of the alkylated $\left(\mathrm{G}_{2}\right)$ dendron-MWNT 6 used for the complete characterization.

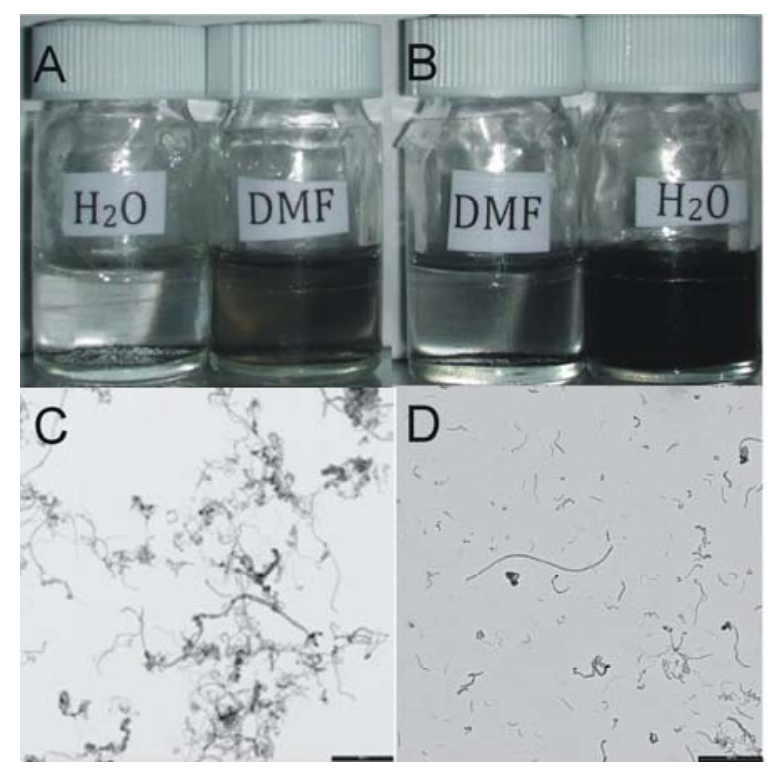

Figure S1. (A) $\left(\mathrm{G}_{2}\right)$ dendron-MWNT $5(0.3 \mathrm{mg})$ in $3 \mathrm{~mL}$ of DMF and $\mathrm{H}_{2} \mathrm{O}$, respectively; (B) alkylated $\left(\mathrm{G}_{2}\right)$ dendron-MWNT $6(0.3 \mathrm{mg})$ in $3 \mathrm{~mL}$ of DMF and $\mathrm{H}_{2} \mathrm{O}$, respectively. (C) TEM image of $\left(\mathrm{G}_{1}\right)$ dendron-MWNT 3 (from water), and (D) TEM image of alkylated $\left(\mathrm{G}_{2}\right)$ dendron-MWNT 6 (from water). Scale bar is $1 \mu \mathrm{m}$. 
The water solubility of conjugate 6 was tenfold higher than conjugate 5 with solubility of $3 \mathrm{mg} / \mathrm{ml}$ and $0.1 \mathrm{mg} / \mathrm{ml}$, respectively. Figure S1A shows that dendron-MWNT 5 disperses better in DMF, with relatively low solubility in water. Alkylated conjugate 6, on the other hand, exhibits reversed behavior, with enhanced solubility in water (Figure S1B). TEM images confirm the presence of MWNTs, showing morphological differences for the different dendron generations in water, including a remarkable increase in the degree of dispersibility (Figure S1C and S1D).

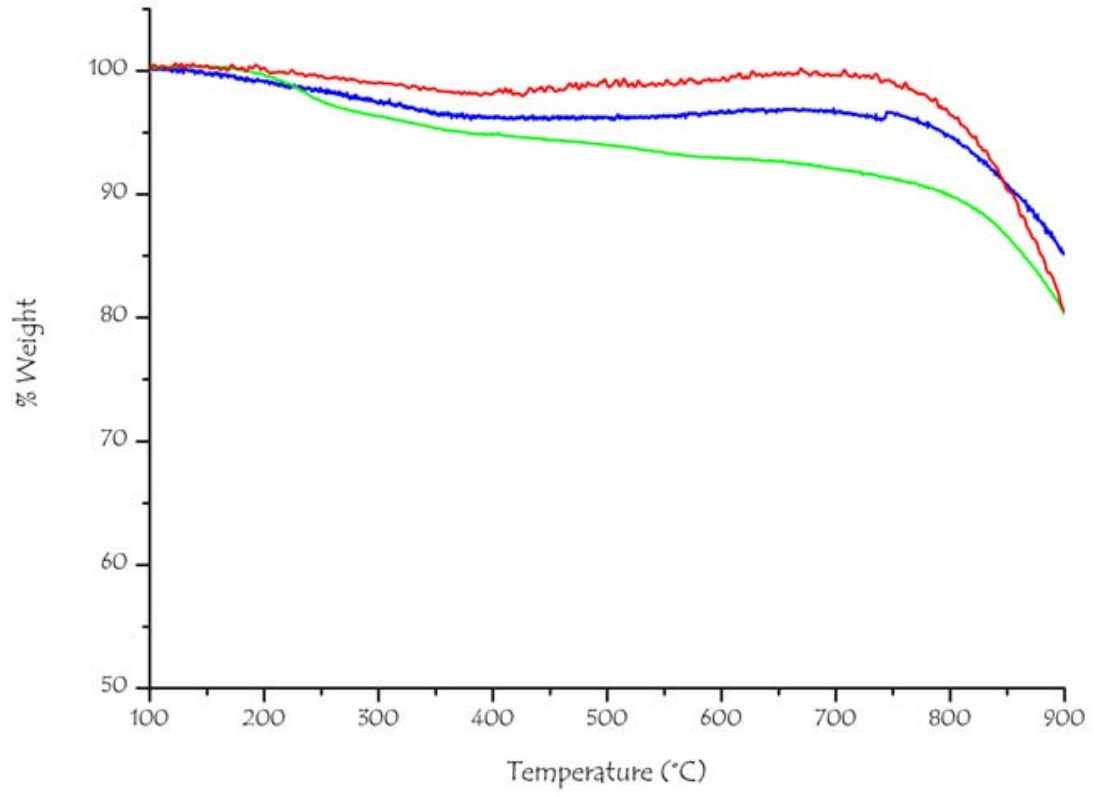

Figure S2. TGA curves of alkylated $\left(\mathrm{G}_{0}\right)$ dendron MWNTs 2 (red line), alkylated $\left(\mathrm{G}_{1}\right)$ dendron-MWNT 4 (blue line), alkylated $\left(\mathrm{G}_{2}\right)$ dendron-MWNT 6 (green line). All the experiments were performed under $\mathrm{N}_{2}$ atmosphere. 

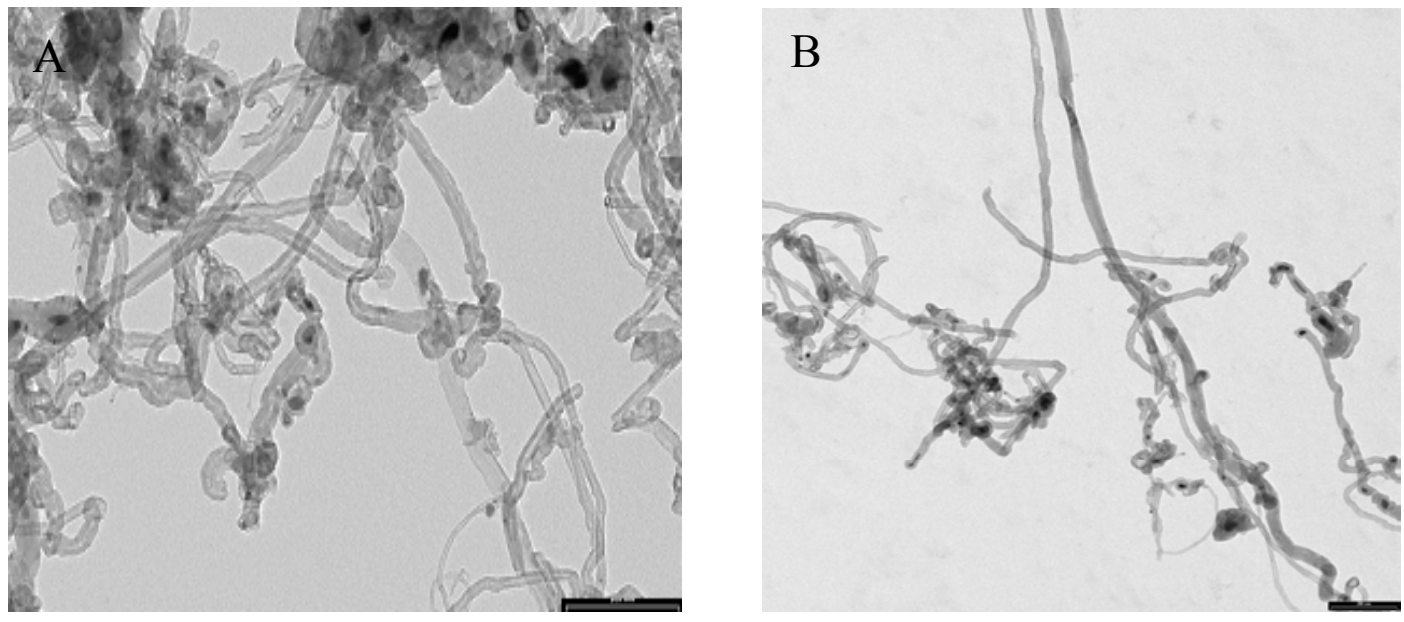

Figure S3. TEM image of (A) Boc-amino protected MWNTs 1 (after 1,3-dipolar cycloaddition), and (B) precursor of dendron-MWNT 5 (after methyl acrylate reaction). Scale bar: $200 \mathrm{~nm}$.
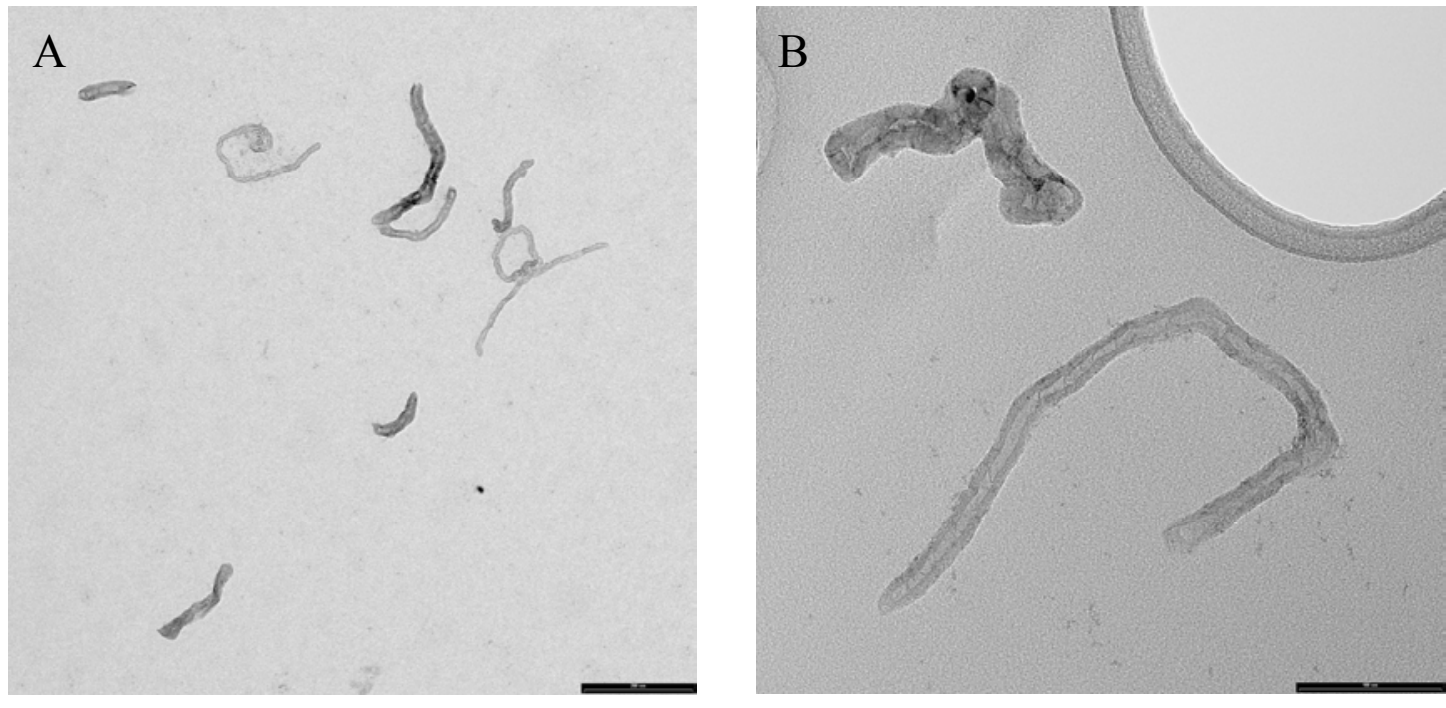

Figure S4. TEM images of dendron-MWNT 6. Scale bar: $200 \mathrm{~nm}(\mathrm{~A})$ and $100 \mathrm{~nm}$ (B).

\section{Full reference 4d:}

Lacerda, L.; Soundararajan, A.; Singh, R.; Pastorin, G.; Al-Jamal, K. T.; Turton, J.; Frederik, P.; Herrero, M. A.; Li, S.; Bao, A.; Emfietzoglou, D.; Mather, S.; Phillips, W. T.; Prato, M.; Bianco, A.; Goins, B.; Kostarelos, K. Adv. Mater. 2008, 20, 225-230. 